\title{
0 aceno do sentido - A fotografia e o haikai por Roland Barthes
}

The waving of sense - photography and haikai by Roland Barthes

Iury Carlos Bueno

Doutor em Comunicação e Semiótica pela PUC/SP. Professor adjunto da Universidade Federal do Amazonas (UFAM)/ICSEZ/Parintins - AM-Brasil iurycbueno@gmail.com

Resumo: As primeiras investidas de Roland Barthes sobre a possibilidade comparativa entre a fotografia e o haikai datam da década de 1970, com o livro $O$ império dos signos, e vão se estender pelo restante do trabalho dele durante uma década, até culminar com o livro A câmara clara. Antes disso, no período letivo que vai de 1978 a 1980, no curso intitulado A preparação do romance, ministrado no Collège de France, posteriormente compilado em livro, Barthes dedicará praticamente oito semanas, exclusivamente, à forma de fazer poética oriental e sua sugestão fotográfica. O subjetivo e o imaginário, que já tinham assento reservado em toda a obra barthesiana, são aqui reconfirmados. Essa insistência na força da escritura singular diante de uma pretensa objetividade do mundo, pretendida por muitos, mas incapaz de dar conta das aflições emotivas que nos movem nesse universo de signos, parece assegurar a Barthes ver o haikai, e também a fotografia, como uma forma particularmente exemplar de alcançar o peculiar em detrimento da totalidade.

Palavras-chave: Roland Barthes. Fotografia. Haikai.

\begin{abstract}
Roland Barthes' first ventures into the comparative possibility between photography and haikai date back to the 1970s with the book The empire of signs, and will span the rest of his work for a decade, culminating in the book Camera lucida. Before that, in the period between 1978 and 1980, in the course entitled The preparation of the novel, ministered in the Collège de France, later compiled in book, Barthes dedicate almost eight weeks, exclusively, to the way of doing Eastern poetry and his photographic suggestion. The subjective and the imaginary, which had already been reserved in all of the Barthesian work, are here reconfirmed. This insistence on the force of singular writing before a pretended objectivity of the world, intended by many but unable to account for the emotional afflictions that move us in this universe of signs, seems to ensure Barthes see haikai and also photography as a particularly exemplar of achieving the peculiar to the detriment of the totality.
\end{abstract}

Keywords: Roland Barthes. Photography. Haikai. 


\section{N. B.}

Toda vez que optarmos pela palavra "haicai" nesta forma, será para manter a preferência de Barthes e outros autores como Haroldo de Campos por esse tipo de grafia. Todavia, na nossa voz, optamos pela grafia "haikai", proposta por autores nacionais estudiosos do assunto como Franchetti, Verçosa, Leminski.

No curso intitulado A preparação do romance, na aula do dia 06 de janeiro de 1979, Barthes inicia com o tema: HAICAI - "MEU HAICAI". Indivíduo e individuação parecem ser as primeiras manifestações da paixão barthesiana pelo tema: "o haicai vai no sentido de uma individuação intensa, sem compromisso com a generalidade" (BARTHES, 2005, p. 82). Não são poucas as tentativas do mestre francês em definir essa forma de manifestação poética. Vejamos: "O haicai nunca descreve: sua arte é contradescritiva, na medida em que todo estado da coisa é imediatamente, obstinadamente, vitoriosamente convertido numa essência frágil de aparição" (BARTHES, 2007, p. 101). É nessa imunidade descritiva que o haikai se protege contra as imposições das definições, das significações. Ao ser por natureza incapaz de definir, o haikai se isenta das amarras do discurso "verdadeiro" ou sentimental. Para Perrone-Moisés, o que fascina Barthes no haikai é que essa forma poética nos dá a possibilidade de ir contra a corrente dos sentidos exauridos da linguagem ocidental, fugir dos círculos semânticos "viciados e viciantes" em que os sentidos de tão abundantes tendem a se auto-anular. Segundo ela,

o que diz o haicai é um momento intensamente vivido por "alguém", mas fixado em linguagem sem o peso do sujeito psicológico do Ocidente. Nenhuma moral da história. O haicai é, para Barthes, um lugar feliz em que a linguagem descansa do sentido. (PERRONE-MOISÉS apud BARTHES, 1989, p. 87).

O haikai não tem pretensões intelectuais. Como uma "bomba" poética, os micropoemas nos agridem com a sua aversão ao discurso intelectualizado, tão caro a nós, ocidentais, e nos jogam no absurdo da realidade crua e sem o mascaramento do sentido. O que definir de textos como esses?

o mar escurece

a voz das gaivotas 


\title{
quase branca (BASHÔ apud LEMINSKI, 2013, p. 104)
}

ou:

\author{
todo ano \\ pensando nos crisântemos \\ sendo pensado \\ pelos mesmos (SHIKI apud LEMINSKI, 2013, p. 104).
}

Nada a dizer: somente constatar, "é isso". É um instante, um retorno da experiência vivenciada pelo poeta, atingindo o leitor com a mesma força sensitiva.

Parece justo dizer, nos valendo de uma reflexão de Didi-Huberman (2010, p. 55-59), sobre a arte minimalista norte-americana de meados do séc. XX, que o haikai parece ir também numa busca tautológica em sua manifestação de signo. Esse sonho visual da coisa mesma, sem outro significado que não ela, a promoção do objeto a uma unidade ausente de significações (portanto sem equívocos), sem esconder nada e nada pedir em troca, toca também o haikai de certa maneira. $\mathrm{O}$ próprio Barthes sugere essa possibilidade também na fotografia.

Por natureza, a Fotografia (é preciso por comodidade aceitar esse universal, que por enquanto apenas remete à repetição incansável da contingência) tem algo de tautológico: um cachimbo, nela, é sempre um cachimbo, intransigentemente (BARTHES, 1984, p. 15).

Para uma possibilidade desta ocorrer, a representação deveria ser incisiva, exata, bastando o fato de olhá-la para entendê-la. Esse objeto específico em que "sempre diante dessa obra você vê o que vê, sempre diante dessa obra você verá o que viu: a mesma coisa". Nessa relação sui generis com o tempo e o espaço, o haikai e a fotografia seriam espécies de objetos representativos específicos que podem (pelo menos teoricamente) escapar do jogo das significações, dos enganos, tornando-se signos de estabilidade tanto visual como semiótica: isto é isto e pronto! A respeito de certos objetos, Didi-Huberman afirma: "diante deles, nada haverá a crer ou a imaginar, uma vez que não escondem nada, nem mesmo o fato de poderem ser vazios [...] tudo parece advogar em favor de uma arte esvaziada de toda conotação" (2010, p. 59). 
Para entendermos o processo que levou Barthes a afirmar: "minha proposta é que o haicai se aproxima muito do noema da fotografia: "Isso foi" [. . . Portanto, minha proposta de trabalho é que o haicai dá a impressão (não a certeza: urdoxa, noema da fotografia) de que aquilo que ele enuncia aconteceu, absolutamente" (BARTHES, 2005, p. 148), é necessário adentrar, mesmo que rapidamente, em A câmara clara. O fato do próprio autor se referir aos termos noema e "isso existiu" nos dá mais um forte indício de que o último livro foi desenvolvido simultaneamente com o curso ministrado no Collège, mesmo que a data oficial de início e término, 15 de abril a 3 de junho de 1979, seja posterior à aula.

Acreditamos que esse diálogo, entre a forma de pensar o curso e a forma de estruturar o livro, são inevitáveis. Nunca é demais salientar que não pretendemos misturar desordenadamente poesia e fotografia, mas apenas acusar, juntamente com Barthes, as virtuais proximidades entre elas. Se o haikai tem semelhança com a fotografia, e isso, para Barthes, parece ser ponto pacífico, que tipo de fotografia é essa?

Uma fotografia, para ser comparada a um haikai, deve ser uma fotografia punctuante (emotiva, que machuca, fere, afirma existencialmente). Elemento sem o qual a fotografia se torna em termos barthesianos "comum", "rasa", "repetitiva", "tediária", "tonitruante". Se, como vimos, no Império dos signos, Barthes já acenava para essa possível ligação, é a partir do conceito de "isso aconteceu, existiu", que tais comparações começam a ganhar mais intensidade. Em 1970, Barthes já havia notado a capacidade do haikai de chegar ao extremo da síntese, do apontamento, da designação. O haikai "reproduz o gesto designador da criança pequena que aponta com o dedo qualquer coisa (o haikai não faz acepção do assunto), dizendo apenas: isto!" (BARTHES, 2007, p. 112-113). A semelhança com a atestação de existência fotográfica é inegável. Em $A$ câmara clara vemos a seguinte afirmação de Barthes relacionando a fotografia ao "gesto da criancinha que designa alguma coisa com o dedo e diz: Ta, Da, Ça!. Uma fotografia sempre se encontra nos extremos desse gesto; ela diz: isso é isso, é tal! mas não diz nada mais" (BARTHES,1984, p.14). Podemos citar um haikai, escrito há mais de trezentos anos (mas extremamente contemporâneo), de Bashô, como exemplar dessa ligação:

matsushima, ah

ah, matsushima, ah 
ah, matsushima (apud LEMINSKI, 2013, p. 18)

ou então, nas palavras de Teishitsu:

\author{
"isto, isto" \\ foi tudo o que pude dizer \\ diante das flores do monte Yoshino (apud BARTHES, 2005, p.165).
}

Tanto haikai, quanto fotografia, agem como índices, traços do real. Ambas as formas representativas dependem do objeto real disposto, num caso, na forma de signo verbal; no outro, como emanação luminosa do referente diante de uma superfície sensível. Tanto em um, quanto em outro, nada a acrescentar, tudo está posto, indefectivelmente. Não há narrativa no haikai, assim como na fotografia há apenas o rapto do instante. Essa irredutibilidade, essa desnecessidade interpretativa, significativa, tão exigente às nossas formas de poesia, reduzem-se ao apontamento: "isso existiu".

Pela marca de alguma coisa, a foto não é mais qualquer. Essa alguma coisa deu um estalo, provocou em mim, um pequeno abalo, um satori, a passagem de um vazio (pouco importa que o referente seja irrisório) [...] o que a ação química desenvolve é o indesenvolvível, uma essência (de ferida), o que não pode transformar-se, mas repetir-se sob as espécies da insistência (do olhar insistente). Isso aproxima a Fotografia (certas fotografias) do Haiku. Pois a notação de um haiku também é indesenvolvível: tudo está dado, sem provocar a vontade ou mesmo a possibilidade de uma expansão retórica (BARTHES,1984, p. 77-78).

Haikai e fotografia são aqui tomados como equivalentes. Ambas as formas são representativas de uma espécie de "iluminação", para usarmos um termo aproximativo comum no universo religioso ocidental. Porém, mais que uma "iluminação", o tilt ou satori seria uma espécie de abdução emotiva e sensorial. Uma forma de eureka onde encontramos o sentido das coisas sem a necessidade da verbalização. É ser tocado por algo ou alguma coisa numa plenitude, numa explosão mental. Podemos compará-lo ao despertar, ao acordar, depois de uma 
longa escuridão. Octavio Paz define esse estado, comparando-o aos instantes de meditação e contemplação: "é um não ser no qual, de alguma maneira, dá-se o pleno ser" (PAZ, 1996, p. 162).

Para Barthes o tilt corresponde, também, ao isso existiu. A beleza de um haikai, tanto como de uma fotografia, se dá justamente em seu talento para silenciar as metalinguagens, como num cubo minimalista de Thony Smith. Forma de registrar rapidamente, em apenas três versos, as manifestações do presente, coloca-se dessa maneira em diálogo direto e adequado às definições do punctum barthesiano. Em outras palavras, há um bloqueio da linguagem. Essa antirepresentação, o episódio, o momento em sua absoluta intensidade e ausência de narratividade, leva Barthes a descobrir no haikai e na fotografia uma válvula de escape ao "mundo ultra significado, mais que significado", a esse inchaço conotativo que tanto aborrece o mundo contemporâneo ocidental. Local de suspensão do pensamento histórico-linear, onde espaço-tempo parecem comungar silenciosamente, afastados da verborragia e do logocentrismo cartesiano. Caderno ou câmera, o haikaista e o fotógrafo se encaixam no perfil do flanêur baudelairiano, do andarilho vagamundo (Bashô era um deles). Como não pensar na fotografia de rua, prática cada vez mais esquecida de contemplação; na ação abdutiva da poesia que desvenda o olhar viciado.

O haicai apetece: quantos leitores ocidentais não sonharam em passear pela vida com um caderninho na mão, anotando aqui e ali algumas "impressões" cuja brevidade garantiria a perfeição, cuja simplicidade atestaria a profundidade (em virtude de um duplo mito, um clássico, que faz da concisão uma prova de arte, outro romântico, que atribui um prêmio de verdade a improvisação). (BARTHES, 2007, p. 90).

Improviso e simplicidade, o acaso acontecendo, contingente, e sendo captado por uma câmera ou peloflash verbal do haikai. Ambos se dão por inteiro, recortes precisos da incerteza da vida.

Ao mesmo tempo que é inteligível, o haicai não quer dizer nada, e é por essa dupla condição que parece ofertado ao sentido de modo particularmente disponível, prestativo, como um hospedeiro 
polido que nos permite instalarmo-nos à vontade em sua casa, com nossas manias, nossos valores, nossos símbolos. (BARTHES, 2007, p. 91).

Haikai epunctum se colocam para além das retóricas, dos comentários, das verborragias. "A fotografia deve ser silenciosa (há fotos tonitruantes, não gosto delas): não se trata de uma questão de "discrição", mas de música" (BARTHES, 1984, p. 84). Essa característica quase mágica, alquímica das duas formas sígnicas, dá, tanto à fotografia quanto ao haikai, uma certa "aura” de pureza que se justifica unicamente no seu estatuto de existência. Foto e haikai tocam emotivamente Barthes por permitirem-no se afastar do ruído, da incessante corrida pelo significado, do blábláblá, da feira, da doxa. Existe, na verdade, em Barthes, um maravilhamento pelo haikai. Numa entrevista dada à Jean-Jacques Brochier, da revista Le Magazin Littéraire, em 1975, ele afirma:

Se eu me imaginar escrevendo outras coisas agora, algumas seriam da ordem do haicai. O haicai é uma forma bem curta, mas que ao contrário da máxima, forma igualmente bem curta, se caracteriza por sua opacidade. Ela não gera sentidos, mas, ao mesmo tempo, não está no não-sentido. (BARTHES, 2004, p. 300).

Barthes justifica, mais uma vez, a predileção pelas formas curtas de escritura, um gosto antigo, e a entende como uma forma que o permite agir contra-ideologicamente, pois a forma curta rompe com o esquema dissertativo, o discurso que tem na sua estrutura a "ideia de um sentido final ao que se diz" (BARTHES, 2004, p. 298). Motta nos lembra que o que aproxima Barthes do haikai é o fato de ele ser: " [. . . ] pura designação sem acontecimentos que não mínimos, e sem comentário do acontecimento, sendo essa a razão de seu encanto" (MOTTA, 2011, p. 94). Mas Barthes é fascinado também pela capacidade do haikai e de algumas fotografias nos levarem ao silêncio, onde a entrega ao sentir vale mais do que o vigor de algum conteúdo suposto. Como neste poema de Buson:

O ruído de um rato

Arranhando um prato

Que frio (apud BARTHES, 2005, p.121). 
O mínimo de linguagem, suscitando a coisa mesma, forma modelar de apresentar o que acontece. Pensar, abstrair por imagens, numa junção momentânea, fotográfica, entre a alteridade, a realidade e o subjetivo mundo interior do poeta, tornando possível materializá-lo em outro tipo de matéria cognitiva-sentimental. Se uma fotografia pode atingir tal capacidade, ela será do tipo que silencia, que machuca, que nos deixa sem comentários, como ao ouvir uma língua desconhecida. Nas palavras de Leminski: "[...] não é a fotografia adocicada de um lótus flutuando no velho tanque de um mosteiro. São feridas, contradições zen, singulares vivências de uma sensibilidade à flor da pele:

pulgas piolhos

um cavalo mija

do lado do meu travesseiro (BASHÔ apud LEMINSKI, 2013, p. 116).

Esse nada a dizer a mais em que nos colocam algumas fotos, bem como o haikai, não significa de modo algum pôr-se em silêncio mutativo, vazio, insignificante, pelo contrário, o silêncio produzido pelo punctum fotográfico e pelo haikai é um silêncio neutralizante que pretende: "[. . . ] agir sobre a própria raiz do sentido, para fazer com que esse sentido não se difunda, não se interiorize, não se torne implícito, não se solte, não divague no infinito das metáforas, nas esferas do símbolo" (BARTHES, 2007, p. 99). O silêncio que Barthes percebe em algumas fotos e nos haikais são signos repletos de significado, apesar de fazer recuar em nós a dependência dos códigos, "[. . .] não se trata de esmagar a linguagem sob o silêncio místico do inefável, mas de comedi-la, de deter esse pião verbal, que carrega em seu giro o jogo obsessivo das substituições simbólicas" (BARTHES, 2007, p. 99). Nada a pôr no "lugar de". Se a grande maioria das fotografias provoca uma tagarelice sem fim, as fotos que Barthes compara ao haikai são discretas, silenciosas, são punctuantes, uma espécie de epifania oriental: "quando compreendi o Zen, as montanhas eram só montanhas e os rios, apenas rios". Esse mesmo Zen que levou Barthes a dizer: "o Zen inteiro guerreia contra a prevaricação do sentido" (BARTHES, 2007, p. 96). E ainda,

todo o Zen, do qual o haicai é apenas o ramo literário, aparece assim como uma imensa prática destinada a deter a linguagem, a quebrar essa espécie de radiofônia interior que se emite continu- 
amente em nós, até em nosso sono (talvez por isso que se impedem os praticantes de dormir), a esvaziar, a estupefazer, a enxugar a tagarelice incoercível da alma. (BARTHES, 2007, p. 98).

O haikai funciona, para Barthes, como um refúgio ao falatório incessante da linguagem, do dínamo mental gerando pensamentos sobre pensamentos, julgamentos sobre julgamentos. Com a fotografia não é diferente,

se a fotografia pertencesse a um mundo que ainda tivesse alguma sensibilidade ao mito, não deixaríamos de exultar diante da riqueza do símbolo: o corpo amado é imortalizado pela mediação de um metal precioso, a prata (monumento e luxo); ao que acrescentaríamos a ideia de que esse metal, como todos os metais da Alquimia, está vivo (BARTHES, 1984, p.121-122).

No caso do haikai, Barthes acrescenta:

O haicai tem a pureza, a esfericidade e o vazio de uma nota musical; é talvez por isso que ele é dito duas vezes, em eco; dizer apenas uma vez essa palavra preciosa seria atribuir um sentido à surpresa, à ponta, à repentinidade da perfeição; dizê-lo várias vezes seria postular que há um sentido a ser descoberto, seria simular a profundidade; entre os dois, nem singular nem profundo, o eco não faz mais do que traçar uma linha sob a nulidade do sentido. (BARTHES, 2007, p. 100).

Para Barthes, a fotografia é a forma de arte que permite conceber o haicai, por ultrapassar os limites do simples diálogo entre texto e imagem, tão comuns contemporaneamente. "Ele sonha com um mundo que fosse isento de sentido [...] é preciso manter a utopia do sentido abolido" (BARTHES, 2003, p. 100-101). É esse vazio que permite ao espectador ou leitor de um texto de entrar na obra sem amarras, sem a densidade do significado dado, sem a arrogância do discurso pronto de antemão.

Barthes, nas aulas do dia 03 de fevereiro e 10 de fevereiro, do curso $A$ preparação do romance, antes de começar a comparar a fotografia ao haikai, 
falará de um tipo de sensação produzida pelo haikai, que pode tê-lo levado a aproximá-lo da fotografia, a esse termo Barthes chama tangibilia. A tangibilia diz respeito àquilo que se pode tocar. No caso do haikai e da fotografia, eles estariam presentes na referencialidade dos signos representados por um meio ou por outro: por palavras, no caso do haikai; por imagens, no caso da fotografia. $\mathrm{O}$ tangibile sempre estaria presente no haikai e encanta Barthes pela característica que foge às estereotipias, como nesse haikai de Bashô:

silêncio

o som das cigarras

penetra as pedras (apud LEMINSKI, 2013, p. 116)

ou nesse de Tôta:

\author{
empregados \\ de branco de manhã \\ fosforescentes \\ como moluscos (apud BARTHES, 2005, p. 116).
}

Barthes se refere ao tangibile, "como um flash do referente, espécie de visão subliminar: a palavra faz ver rapidamente (ao mesmo tempo que desaparece)" (2015, p. 117). Segundo ele, o haikai é um tipo de hipotipose, uma descrição tão vivamente exposta que é capaz de "dar a ver" o próprio objeto. Essa força visual do haikai, esse som cortado, é que nos projeta nesse silêncio misterioso da imagem. O haikai, bem como a fotografia, com a escassa porção de significado, irão assim esgotando as possibilidades do jogo decifrativo, que não o da atestação. Isso leva Barthes a afirmar: o "haicai não me pega, não me atinge, sem tangibile, sem hipotipose" (2015, p. 119). Quem joga única e exclusivamente com o significante tende ao delírio poético, como nas palavras de Manoel de Barros: "[. . . ] no começo era o verbo. Só depois é que veio o delírio do verbo. O delírio do verbo estava no começo, lá onde a criança diz: eu escuto a cor dos passarinhos [...]" (2013, p. 23).

É por seu vigor imagético que o haikai produz em Barthes o mesmo golpe do momento que a fotografia traz. Tal como as escrituras do grau zero, a fotografia é aqui imagem perturbadora e fúnebre, que não se deixa reduzir 
a interpretações verbais, nem a ideologias. O intratável, o inalcançável pelo domínio das palavras é o "retorno do morto" (BARTHES, 1984, p. 20) que atiça em Barthes a substância religiosa. Esse sentimento traumatizante do último Barthes diante de certas fotografias confirma a crença dele no realismo fotográfico e, consequentemente, na imobilidade viva dessas imagens, elementos que o levam a aproximar punctum e haikai - ambos marcados fortemente pela tangibilia e pela hipotipose. O fotógrafo e o poeta aproximam-se pela capacidade de aprisionar momentos, reencontrando-os em anamneses tênues. O próprio haikai é uma anamnese fosca, insignificante: isenta de sentido. Essa lembrança tênue pode se transformar em outro termo, querido por Barthes, denominado biografema. O biografema seria uma forma de anamnese factícia, artificial, dedicadas aqueles a quem ele ama, sejam autores, sejam conhecidos, seja ele próprio (é o reino do imaginário ficcional a partir de algo real), formas de escrever o presente. Para Motta e Fontanari, tanto a fotografia como o haikai são:

Uma espécie de anotação em seu "grau zero, em sua literalidade que atribui toda uma outra dimensão à noção mesma de compreensão. Compreender não é reter o sentido, mas 'apelo ao sentido'. Noutras palavras é um aceno breve do referente sobre o fluxo da vida, tão breve que mal se consegue mantê-lo sobre o pedaço de papel ou sobre a chapa fotográfica”. (2014, p. 136).

É o aceno do real contido na fotografia, assim como no haikai, que interessa a Barthes. Tudo se passa como se, por meio de um ou outro, tocássemos esse real. Tanto a fotografia e o haikai ultrapassam (a generalidade e a narratividade) para se aproximar da acidentalidade efêmera, da Notatio (anotação), capturando fragmentos do presente tal como ele se apresenta à consciência. Essa forma de trabalhar dá ao futuro romancista a equivalência do andarilho, do flâneur, do poeta haikaísta e do fotógrafo. "A Notatio é, pois, uma atividade exterior: não acontece na minha mesa de trabalho, mas na rua, no café, com amigos etc." Para que essa prática se realize há que se ter tempo, estar disponível, sempre disponível, para como um gangster sacar a "câmera-caneta" e fazer perdurar o momento. 


\section{Referências}

BARROS, Manoel de. A biblioteca de Manoel de Barros. São Paulo: Leya, 2013.

BARTHES, Roland. Aula. Tradução Leyla Perrone-Moisés. São Paulo: Cultrix, 1989.

A câmara clara: nota sobre a fotografia. Tradução Júlio Castañon Guimarães.

Rio de Janeiro: Nova Fronteira, 1984.

. A preparação do romance. Vol. I. Tradução Leyla Perrone-Moisés. São Paulo:

Martins Fontes, 2005.

O grão da voz. Tradução Mário Laranjeira. São Paulo: Martins Fontes, 2004.

O império dos signos. Tradução Leyla Perrone-Moisés. São Paulo: Martins

Fontes, 2007.

Roland Barthes por Roland Barthes. Tradução Leyla Perrone-Moisés. São

Paulo: Estação Liberdade, 2003.

DIDI-HUBERMAN, Georges. O que vemos, o que nos olha. Tradução de Paulo Neves. São Paulo: Editora 34, 2010.

LEMINSKI, Paulo. Vida - 4 biografias: Cruz e Sousa, Bashô, Jesus, Trotski. São Paulo:

Companhia das Letras, 2013.

MOTTA, Leda Tenório da. Roland Barthes - uma biografia intelectual. São Paulo:

Iluminuras, 2011.

MOTTA, Leda Tenório da; FONTANARI, Rodrigo. A tentação do haikai e a experiência traumática da fotografia em Roland Barthes. Belo Horizonte: Revista Aletria número 02, vol. 24, 2014.

PAZ, Octavio. Signos em rotação. Tradução Sebastião Uchoa Leite. São Paulo: Perspectiva, 1996.

recebido em 17 maio 2017 / aprovado em 16 jun. 2018

Para referenciar este texto:

BUENO, I. C. O aceno do sentido - A fotografia e o haikai por Roland Barthes. Dialogia,

São Paulo, n. 29, p. 21-32, mai./ago. 2018. Disponível em: < https://doi.org/10.5585/

Dialogia.n29.8687>. 